\title{
The Contribution of Glycolysis, Glucose Oxidation, Lactate Oxidation, and Fatty Acid Oxidation to ATP Production in Isolated Biventricular Working Hearts from 2-Week-Old Rabbits
}

\author{
TOSHIYUKI ITOI AND GARY D. LOPASCHUK \\ Cardiovascular Disease Research Group, Lipid and Lipoprotein Research Group, Department of Pediatrics and \\ Pharmacology, The University of Alberta, Edmonton, Canada
}

\begin{abstract}
Immediately after birth, glycolysis and lactate oxidation are the major source of ATP production in the rabbit heart. Although the ability of heart to oxidize fatty acid increases within days, glucose oxidation rates remain low in the first week after birth. To further examine the changes in energy substrate use in the newborn period, we developed a right and left ventricular isolated working heart model, in which 2-nk-old rabbit hearts were perfused with buffer containing $11 \mathrm{mM}$ glucose, $0.8 \mathrm{mM}$ palmitate, $0.5 \mathrm{mM}$ lactate, and $100 \mu \mathrm{U} / \mathrm{mL}$ insulin. Hearts were perfused at a $7.5 \mathrm{~mm} \mathrm{Hg}$ left atrial preload, a $4.5 \mathrm{~mm} \mathrm{Hg}$ superior vena cava preload, a $30 \mathrm{~mm} \mathbf{~ g g}$ aortic afterload, and a $4.5 \mathrm{~mm} \mathrm{Hg}$ pulmonary artery afterload. Glycolytic rates [measured as ${ }^{3} \mathrm{H}_{2} \mathrm{O}$ production from $\left(5-{ }^{3} \mathrm{H}\right)$-glucose] were $791 \pm 108 \mathrm{nmol} / \mathrm{g}$ dry weight $\cdot \min ^{-1}$ (mean \pm SEM). Oxidation rates of glucose, lactate, and palmitate (measured as ${ }^{14} \mathrm{CO}_{2}$ production from ${ }^{14} \mathrm{C}$ substrates) were $94 \pm$ $15,126 \pm 13$, and $60 \pm 8 \mathrm{nmol} / \mathrm{g}$ dry weight $\cdot \mathrm{min}^{-1}$, respectively. In these hearts, the majority of ATP production derived from exogenous sources was obtained from fatty acid oxidation (52\%), whereas 11, 23, and $15 \%$ of ATP requirements were derived from glycolysis, glucose oxidation, and lactate oxidation, respectively. These studies demonstrate that by $\mathbf{2}$ wks of age in rabbits, fatty acids are the major source of energy in the heart. However, although the contribution of glucose oxidation to ATP production has increased compared with 1- or 7-d-old rabbit hearts, glucose oxidation rates are still low compared with adult hearts. (Pediatr Res 34: 735-741, 1993)
\end{abstract}

\section{Abbreviations}

CPT 1, carnitine palmitoyltransferase

PDC, pyruvate dehydrogenase complex

LDH, lactate dehydrogenase

PAPSP, pulmonary arterial peak systolic pressure

AoPSP, aortic arterial peak systolic pressure

Received January 20, 1993; accepted July 13, 1993

Correspondence and reprint requests: Dr. Gary D. Lopaschuk, 423 Heritage Medical Research Building, The University of Alberta, Edmonton, Alberta, Canada, T6G 2S2.

Supported by a grant from the Heart and Stroke Foundation of Alberta. G.D.L. is a scholar of the Alberta Heritage Foundation for Medical Research. T.I. is a postdoctoral fellow of the Heart and Stroke Foundation of Canada.
Immediately after birth, the maternal supply of glucose and lactate ceases abruptly and newborns are fed milk, a diet that is high in fat and low in carbohydrates. From this time, newborns quickly develop the metabolic pathways for efficient oxidation of fatty acids by the heart. Immediately after birth, fatty acids are not the major energy substrate in newborn hearts (1-3), although the capacity of the heart to oxidize fatty acids rapidly increases (2-4). A low rate of fatty acid oxidation may in part be governed by low rates of mitochondrial CPT 1 activity after birth $(5,6)$.

In rabbits, we recently demonstrated that before the maturation of fatty acid oxidation, glycolysis and lactate oxidation are the major sources of ATP production in the heart (2). Although glucose oxidation is a prominent source of ATP production in adult hearts, glucose oxidation rates are very low in the newborn heart (3). In contrast, lactate, which can be readily oxidized by fetal hearts $(7,8)$, is a major source of ATP production in 1- and 7-d-old rabbit hearts (3). In adults, lactate oxidation is thought to be less important as a source of ATP production, although higher concentrations of lactate can reduce the rate of release and oxidation of fatty acids $(9,10)$. Lactate also decreases glucose oxidation, but to a lesser degree than fatty acid oxidation (10). Although lactate is a potent inhibitor of both glucose and palmitate oxidation in newborn rabbit hearts $(3,8)$, the relationship between carbohydrate and fatty acid metabolism in the developing heart has still to be clearly established.

Even though mechanical load to the right ventricle decreases immediately after birth, the systolic pressure of the right ventricle remains high during the early perinatal period. Because mechanical function and oxidative metabolism are closely linked in the heart (11), it is probable that right ventricular performance is an important determinant of myocardial metabolism. This may be particularly important in the newborn heart where the right ventricular load is high. To date, however, overall myocardial metabolism in which a work load is imposed on the right ventricle has not been studied in detail. Werner's group has used isolated working hearts perfused via the inferior vena cava to study myocardial metabolism in fetal and newborn pigs $(1,12)$. We have also adapted this protocol to newborn rabbits to measure energy substrate use in the immediate newborn period $(2,3)$. However, the perfusion system is only suitable in the early neonatal period, because it requires that the foramen ovale remain patent.

The purposes of this study were 1 ) to develop a right and left ventricular isolated working heart model that realizes physiologic states experienced by neonatal hearts and 2) to further examine the changes in exogenous energy substrate use in the neonatal period. The biventricular working heart model developed in this study demonstrates that right ventricular performance is an 
important component of myocardial metabolism during the perinatal period. The increase in ATP demand produced by imposing a right ventricular load on the heart is selectively met by an increase in fatty acid oxidation. By directly measuring myocardial glucose, lactate, and palmitate oxidation in these hearts, we demonstrate that fatty acid and glucose oxidation become the primary energy source of the heart by 2 wk of age in the rabbit.

\section{MATERIALS AND METHODS}

D- $\left[\mathrm{U}_{-}{ }^{14} \mathrm{C}\right]$ glucose, D- $\left[5-{ }^{3} \mathrm{H}\right]$ glucose, $\mathrm{L}-\left[\mathrm{U}-{ }^{14} \mathrm{C}\right]$ lactate, and [1${ }^{14} \mathrm{C}$ palmitate were obtained from DuPont-New England Nuclear (Wilmington, DE). BSA (fraction V) was obtained from Boehringer Mannheim (Indianapolis, IN). Insulin (regular) was obtained from Connaught Novo (Willowdale, Ontario, Canada). Hyamine hydroxide (1 M in methanol solution) was obtained from New England Nuclear Research Products (Boston, MA). Dowex 1X4 anion exchange resin (200-400 mesh chloride form) was obtained from Bio-Rad Laboratories (Richmond, CA). ACS Aqueous Counting Scintillant was obtained from Amersham Canada Ltd. (Oakville, Ontario, Canada). All other chemicals were obtained from Sigma Chemical Company (St. Louis, MO).

Heart perfusions. Two-wk-old New Zealand White rabbits were separated from the doe on the morning of experimentation. The animals were cared for according to the guidelines of the Canadian Council on Animal Care. The body weight of these 2wk-old rabbits was $220 \pm 13 \mathrm{~g}$, and heart weight was $1.23 \pm 0.07$ g.

Rabbits were injected with an overdose of Na-pentobarbital $(60 \mathrm{mg} / \mathrm{kg})$. When the rabbit totally lacked sensation, the thoracic cavity was quickly opened and the heart and lungs were excised without the pericardium and placed in Krebs-Henseleit buffer. Hearts were cannulated via the aorta and a retrograde (Langen-

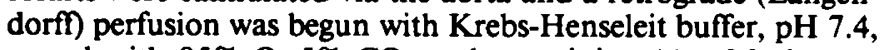
gassed with $95 \% \mathrm{O}_{2}-5 \% \mathrm{CO}_{2}$ and containing $11 \mathrm{mM}$ glucose, $100 \mu \mathrm{U} / \mathrm{mL}$ insulin, and $1.25 \mathrm{mM}$ free $\mathrm{Ca}^{2+}$. The elapsed time between opening the thoracic cavity and initiating this retrograde perfusion never exceeded $30 \mathrm{~s}$. The retrograde perfusion was continued for $10 \mathrm{~min}$, during which the opening to the left atrium was cannulated and lungs were removed. Hearts were then switched to the classic working mode by initiating perfusion via the left atrial cannula at a constant $7.5 \mathrm{~mm} \mathrm{Hg}$ left atrial preload and a $30 \mathrm{~mm} \mathrm{Hg}$ hydrostatic aortic afterload. At this time, both the main pulmonary artery and superior vena cava were isolated and cannulated. The inferior vena cava was also isolated, then ligated. To initiate flow to the right ventricle, perfusate was delivered to the right atrium via the superior vena cava cannula at the pressures indicated in the individual experiments. A diagram of the biventricular working heart preparation is shown in Figure 1.

Heart rate and peak systolic pressure development were continuously monitored using a Gould P21 pressure transducer inline with the aortic or pulmonary outflow line. The rate-pressure product was calculated by multiplying peak systolic pressure by heart rate. Aortic and a pulmonary output were measured manually from both afterload lines.

Perfusion conditions. Isolated biventricular working hearts were perfused with Krebs-Henseleit buffer ( $\mathrm{pH} 7.4$ ), gassed with $95 \% \mathrm{O}_{2}-5 \% \mathrm{CO}_{2}$. Perfusate contained $11 \mathrm{mM}$ glucose, $0.8 \mathrm{mM}$ palmitate, $0.5 \mathrm{mM}$ lactate, $1.25 \mathrm{mM}$ free $\mathrm{Ca}^{2+}, 100 \mu \mathrm{U} / \mathrm{mL}$ insulin, and 3\% BSA. Palmitate was prebound to the albumin. In an initial series of experiments, hearts were perfused at a 7.5 $\mathrm{mm} \mathrm{Hg}$ left atrial preload and $30 \mathrm{~mm} \mathrm{Hg}$ aortic afterload and a superior vena cava and pulmonary artery afterload of either 4.5 , 6.0 , or $7.5 \mathrm{~mm} \mathrm{Hg}$ (see individual experiments). In experiments involving myocardial energy substrate use, hearts were perfused for $20 \mathrm{~min}$ at a $7.5 \mathrm{~mm} \mathrm{Hg}$ left atrial preload, $4.5 \mathrm{~mm} \mathrm{Hg}$ pulmonary arterial afterload, and $30 \mathrm{~mm} \mathrm{Hg}$ aortic afterload, followed by an additional $40-\mathrm{min}$ period in which a $4.5 \mathrm{~mm} \mathrm{Hg}$ superior vena cava preload was applied.

Measurement of glycolysis, glucose oxidation, palmitate oxidation, and lactate oxidation. Glycolysis and glucose oxidation were measured simultaneously by perfusing hearts with $100 \mathrm{~mL}$ of Krebs-Henseleit buffer containing $11 \mathrm{mM}\left[5-{ }^{3} \mathrm{H} / \mathrm{U}-{ }^{14} \mathrm{C}\right] \mathrm{glu}-$ cose (sp act of perfusate was $40000 \mathrm{dpm}$ of ${ }^{3} \mathrm{H} / \mu \mathrm{mol}$ glucose and $40000 \mathrm{dpm}$ of ${ }^{14} \mathrm{C} / \mu \mathrm{mol}$ glucose). To measure palmitate oxidation, a series of rabbit hearts were perfused under the same conditions except that $\left[1-{ }^{14} \mathrm{C}\right]$ palmitate (sp act of perfusate equaled $400000 \mathrm{dpm}$ of ${ }^{14} \mathrm{C} / \mu \mathrm{mol}$ palmitate) was used instead of labeled glucose. To measure lactate oxidation, a series of rabbit hearts were perfused as described above, except $\left[\mathrm{U}-{ }^{14} \mathrm{C}\right]$ lactate (sp act of perfusate was $40000 \mathrm{dpm}$ of ${ }^{14} \mathrm{C} / \mu \mathrm{mol}$ lactate) was used instead of labeled glucose or palmitate. In all hearts, quantitative ${ }^{14} \mathrm{CO}_{2}$ production from appropriately labeled carbon substrates was determined by measuring both perfusate and gaseous ${ }^{14} \mathrm{CO}_{2}$ production $(2,3)$. Rates of oxidation were based on the sp act of the radiolabeled ${ }^{14} \mathrm{C}$ substrate in the recirculated buffer. As shown in Figure 1, perfusate from a central reservoir is pumped to individual preload oxygenation chambers before entering the heart. Perfusate released from each ventricle, which contains the ${ }^{14} \mathrm{CO}_{2}$, flows laterally back into the central reservoir through each afterload line. Perfusate overflow from each preload chamber also returns to the central heart chamber. As a result, the ${ }^{14} \mathrm{CO}_{2}$ in the perfusate is in equilibrium. The gaseous ${ }^{14} \mathrm{CO}_{2}$ released from each oxygenator is also quantitatively collected. Therefore, rates of oxidation metabolism are based on overall ${ }^{14} \mathrm{CO}_{2}$ production by the heart, based on the sp act of the ${ }^{14} \mathrm{C}$ carbon substrate in the perfusate.

Glycolytic rates were determined by quantitatively measuring ${ }^{3} \mathrm{H}_{2} \mathrm{O}$ production $\left({ }^{3} \mathrm{H}_{2} \mathrm{O}\right.$ is liberated at the enolase step of glycolysis). To measure glycolysis, ${ }^{3} \mathrm{H}_{2} \mathrm{O}$ was separated from ${ }^{3} \mathrm{H}$-glucose and ${ }^{14} \mathrm{C}$-glucose as previously described $(13,14)$, using columns containing Dowex 1-X4 anion exchange resin suspended in 0.2 $M$ potassium tetraborate. Glucose utilization was expressed as $\mathrm{nmol}$ glucose metabolized/min $\cdot \mathrm{g}$ dry weight ${ }^{-1}$.

Calculation of ATP production. Steady state rates of ATP production from exogenous substrates were calculated using the steady state rates of glycolysis and glucose, lactate, and palmitate oxidation obtained from experiments in which $11 \mathrm{mM}$ glucose, $0.5 \mathrm{mM}$ lactate, $0.8 \mathrm{mM}$ palmitate, $3 \%$ albumin, and $100 \mu \mathrm{U} /$ $\mathrm{mL}$ insulin were present in the perfusate. Values of $2 \mathrm{~mol}$ of ATP produced/mol of glucose passing through glycolysis, $36 \mathrm{~mol}$ of ATP produced $/ \mathrm{mol}$ of glucose oxidized, $18 \mathrm{~mol}$ of ATP produced $/ \mathrm{mol}$ of lactate oxidized, and $129 \mathrm{~mol}$ of ATP produced $/ \mathrm{mol}$ of palmitate oxidized were used.

Statistical analysis. Analysis of variance followed by the Kruskal-Wallis test was used in the determination of statistical difference in groups containing three or more sample populations. The Mann-Whitney test was used for statistical significance of two group means. A value of $p<0.05$ was considered as significant. All data are presented as mean \pm SEM (number in each group).

\section{RESULTS}

Two-wk-old rabbit heart perfusions. In this study, we chose a preload for the left atrium of $7.5 \mathrm{~mm} \mathrm{Hg}$ and an afterload for the left ventricle of $30 \mathrm{~mm} \mathrm{Hg}$. These parameters were used because we have shown that they represent near maximal workloads in neonatal rabbit hearts $(2,14)$. Afterload and preload curves were initially performed to determine the optimal loading condition by which the hearts can maintain maximum function.

To determine the most suitable right-side loading conditions (preload to right atrium and afterload to right ventricle), we chose from preliminary studies hydrostatic pressures of 4.5, 6.0, or $7.5 \mathrm{~mm} \mathrm{Hg}$. In these experiments, hearts were perfused at the same pulmonary arterial afterload used for the right ventricular preload. The criteria to determine the best loading condition 


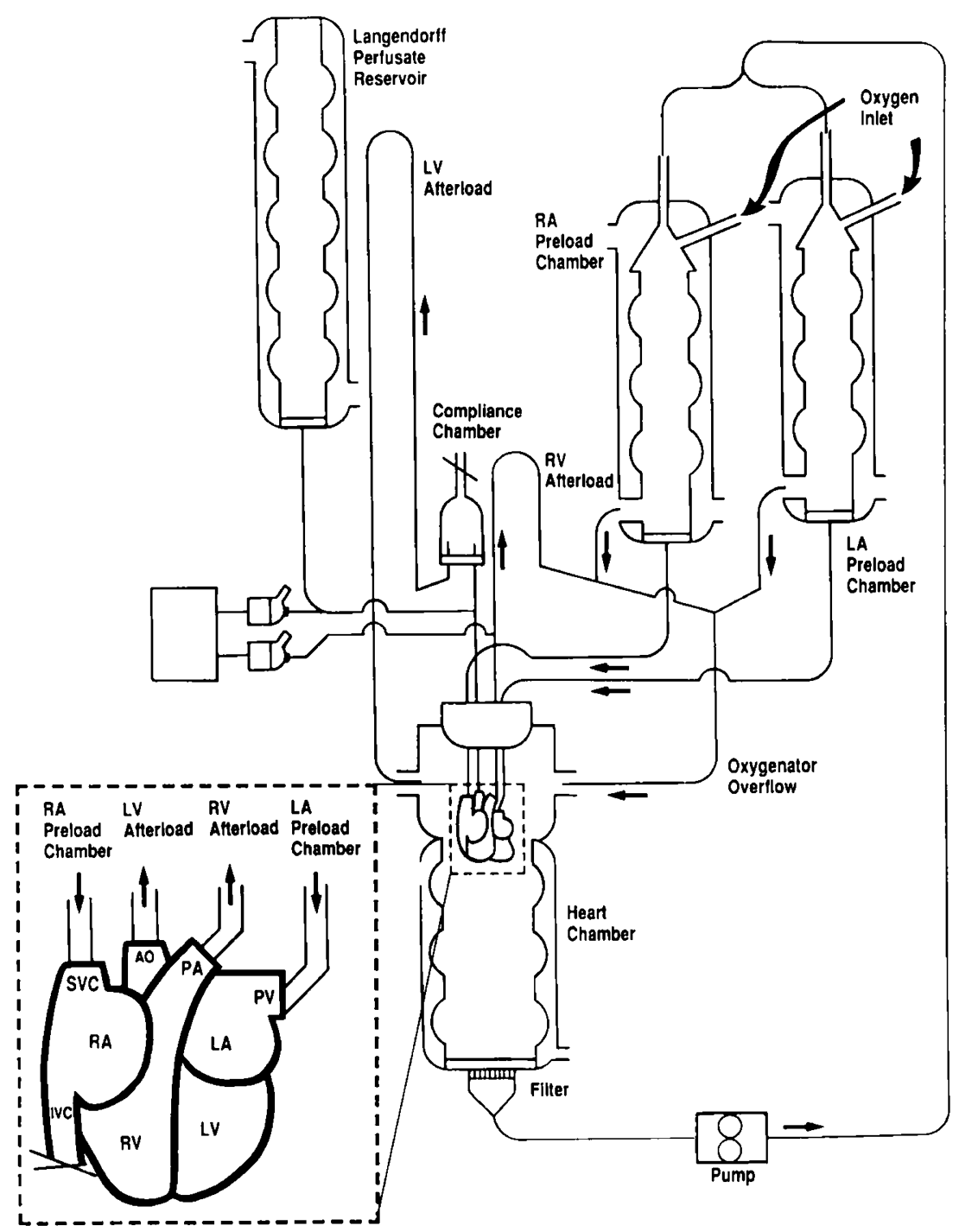

Fig. 1. Diagram of the biventricular isolated working heart. Perfusate is delivered to the left ventricle $(L V)$ at a $7.5 \mathrm{~mm} \mathrm{Hg}$ preload from a left atrial $(L A)$ cannula, which receives buffer from a left atrial oxygenator. Perfusate is ejected from the left ventricle against a $30 \mathrm{~mm} \mathrm{Hg}$ afterload. The right ventricle $(R V)$ receives perfusate from a superior vena cava $(S V C)$ cannula at a $4.5 \mathrm{~mm} \mathrm{Hg}$ preload from the right atrial oxygenator. Perfusate from the right ventricle is ejected into the pulmonary artery $(P A)$ at a $4.5 \mathrm{~mm} \mathrm{Hg}$ afterload. Aortic $(A O)$ and pulmonary arterial $(P A)$ pressure are monitored with in-line pressure transducers. The entire system is sealed, allowing quantitative collection of ${ }^{14} \mathrm{CO}_{2}$ for measurement of oxidative metabolism. $I V C$, inferior vena cava.

were 1) PAPSP should be $30-40 \%$ of AoPSP, 2) over $90 \%$ of the initial left ventricular function should be maintained over the 50 -min perfusion period, and 3) no decrease in hydrostatic pressure of left ventricular afterload should occur over the 50 min perfusion period.

Heart function in hearts perfused at a $4.5,6.0$, or $7.5 \mathrm{~mm} \mathrm{Hg}$ superior vena cava preload and pulmonary arterial afterload is shown in Table 1 and Figure 2. At a $7.5 \mathrm{~mm} \mathrm{Hg}$ pressure, the PAPSP exceeded $50 \%$ of the AoPSP. In hearts perfused at 4.5 $\mathrm{mm} \mathrm{Hg}$ and $6.0 \mathrm{~mm} \mathrm{Hg}$ right-side loading pressures, the PAPSP was $34 \%$ of the AoPSP. In hearts perfused at a right-side pressure of 6.0 and $7.5 \mathrm{~mm} \mathrm{Hg}$, left ventricular function (expressed as heart rate $\times$ AoPSP) gradually decreased during $30 \mathrm{~min}$ of perfusion. Only hearts perfused at a $4.5 \mathrm{~mm} \mathrm{Hg}$ superior vena cava preload and pulmonary arterial afterload maintained left ventricular function over the perfusion period (Fig. 2). Based on these observations, we chose to use a $4.5 \mathrm{~mm} \mathrm{Hg}$ superior vena cava preload and pulmonary artery afterload in subsequent experiments in which energy substrate preference was measured. Figure 3 shows the effect of imposing a right ventricular load on left and right ventricular function. Heart rate $\times$ PAPSP could be recorded before initiation of the right-side perfusion, because coronary effluent from the left-sided preparation was emptying into the right side and was ejected into the pulmonary circulation. An aortic and a pulmonary output were measured manually from both afterload lines. No change was observed in both AoPSP $\times$ heart rate and PAPSP $\times$ heart rate after initiation of the right-side perfusion (Fig. $3 a$ ). On the contrary, the addition of the right-side perfusion increased mean flow rates from pulmonary artery dramatically (Fig. $3 b$ ).

Glycolysis and glucose oxidation rates in 2-wk-old rabbit hearts. Cumulative glycolysis throughout the perfusion period is shown in Figure $4 .{ }^{3} \mathrm{H}_{2} \mathrm{O}$ production from $\left(5-{ }^{3} \mathrm{H}\right)$-glucose was constant and cumulatively linear throughout the entire procedure. Steady state rates of glycolysis are shown in Table 2 . No increase was seen after initiation of the right-side perfusion.

Cumulative glucose oxidation throughout the perfusion period is shown in Figure $5 .{ }^{14} \mathrm{CO}_{2}$ production from $\left(\mathrm{U}-{ }^{14} \mathrm{C}\right)$-glucose was constant throughout the perfusion period. As shown in Table 2, no increase in steady state glucose oxidation rates were seen after the initiation of the right-side perfusion. It should also be noted that glucose oxidation rates were substantially lower than glyco- 
Table 1. Effects of various superior vena cava preloads and pulmonary arterial afterloads on mechanical function in isolated working hearts from 14-d-old rabbits*

\begin{tabular}{lccc}
\hline \multicolumn{1}{c}{$\begin{array}{c}\text { Parameter } \\
\text { measured }\end{array}$} & \multicolumn{3}{c}{ Preload and afterload } \\
\cline { 2 - 4 } & $4.5 \mathrm{~mm} \mathrm{Hg}(n=19)$ & $6.0 \mathrm{~mm} \mathrm{Hg}(n=3)$ & $7.5 \mathrm{~mm} \mathrm{Hg}(n=11)$ \\
\hline At initiation of perfusion & & & $182 \pm 7$ \\
HR & $189 \pm 7$ & $184 \pm 11$ & $49 \pm 3$ \\
AoPSP & $52 \pm 1$ & $50 \pm 2$ & $25 \pm 1$ \\
PAPSP & $18 \pm 1$ & $17 \pm 1$ & $8.9 \pm 0.6$ \\
HR $\times$ AoPSP & $9.9 \pm 0.5$ & $9.2 \pm 0.8$ & $195 \pm 16$ \\
30 min into perfusion & $207 \pm 6$ & $176 \pm 8$ & $34 \pm 5 \dagger$ \\
HR & $45 \pm 2$ & $45 \pm 2 \dagger$ & $28 \pm 2$ \\
AoPSP & $19 \pm 1$ & $15 \pm 1$ & $5.6 \pm 1.1 \dagger$ \\
PAPSP & $9.3 \pm 0.5$ & $8.0 \pm 0.6$ & \\
HR $\times$ AoPSP &
\end{tabular}

* Hearts were perfused with $11 \mathrm{mM}$ glucose, $0.5 \mathrm{mM}$ lactate, $0.8 \mathrm{mM}$ palmitate, $3 \%$ albumin, and $100 \mu \mathrm{U} / \mathrm{mL}$ insulin as described in Materials and Methods. Values are the mean \pm SEM of the number of hearts shown in parentheses. HR, heart rate.

† Significantly different from that at the initiation of the perfusion.

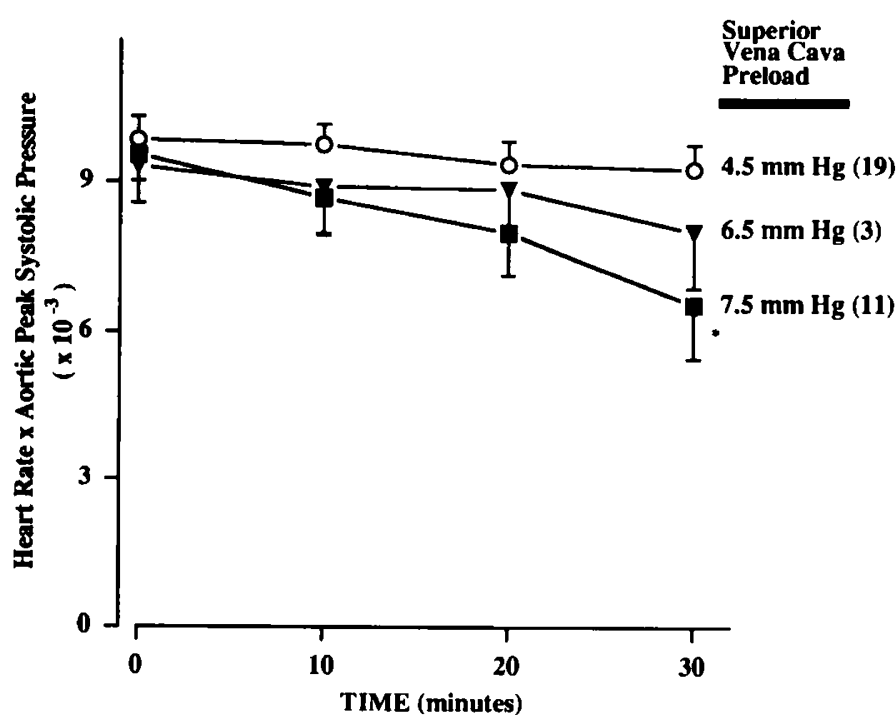

Fig. 2. Effects of various superior vena cava preloads and pulmonary afterloads on left ventricular function in isolated working hearts from 14-d-old rabbits. Heart rate $\times$ aortic peak systolic pressure was measured in hearts perfused via both the superior vena cava and via left atrium as described in Materials and Methods. Left atrial preload and aortic afterload were $7.5 \mathrm{~mm} \mathrm{Hg}$ and $30 \mathrm{~mm} \mathrm{Hg}$, respectively. Hearts were perfused with variable superior vena cava preload and pulmonary afterloads $(4.5,6.0$, and $7.5 \mathrm{~mm} \mathrm{Hg})$ for $30 \mathrm{~min}$. Values are the mean \pm SEM (number in each group). ${ }^{*}$, significantly different than at the initiation of the perfusion.

lytic rates in these hearts. This high ratio of glycolysis to glucose oxidation is similar to our previous work in 1- and 7-d-old rabbits, which suggests that in fatty acid-perfused hearts glycolytic rates are much higher than glucose oxidation rates $(13,14)$.

Lactate oxidation rates in 2-wk-old rabbit hearts. Cumulative lactate oxidation rates are shown in Figure $6 .{ }^{14} \mathrm{CO}_{2}$ production from $\left(\mathrm{U}-{ }^{14} \mathrm{C}\right)$-lactate increased slightly after the initiation of the right-side perfusion. Steady state lactate oxidation rates are shown in Table 2. A small but significant increase in lactate oxidation by the whole heart was seen after initiation of the right-side perfusion (Fig. 6, Table 2).

Palmitate oxidation rates in 2-wk-old rabbit hearts. Cumulative palmitate oxidation rates are shown in Figure $7 .{ }^{14} \mathrm{CO}_{2}$ production from $\left(1-{ }^{14} \mathrm{C}\right)$-palmitate increased linearly during the left-sided perfusion, and then accelerated after initiation of rightside perfusion. Steady state palmitate oxidation rates are shown in Table 2. A significant increase in palmitate oxidation by the whole heart was seen after initiation of the right-side perfusion (Fig. 7, Table 2).

Steady state ATP production in 2-wk-old rabbit hearts. Using the steady state rates of glycolysis, glucose oxidation, lactate oxidation, and palmitate oxidation shown in Table 2, steady state rates of ATP production from exogenous sources were calculated in the 14-d-old rabbit hearts. As shown in Table 3, addition of a right-side perfusion increased total ATP production by $50 \%$ (from 10018 to $15045 \mathrm{nmol} / \mathrm{g} \mathrm{dry} \cdot \mathrm{min}^{-1}$. This increase in ATP production was primarily derived from an increase in palmitate oxidation. In hearts in which a right-sided perfusion was present, palmitate and glucose were the primary source of ATP production, contributing $75 \%$ of the total ATP production.

\section{DISCUSSION}

The mechanical work performed by the heart is the key determinant of ATP requirements. In this study, we developed and characterized an isolated biventricular isolated working heart model to study myocardial metabolism. Because of the significant size of the right ventricle of neonatal hearts (and therefore its contribution to overall metabolism), this experimental preparation should prove useful in studying developmental changes in myocardial metabolism. Werner et al. $(1,8,12)$ have previously characterized an elegant biventricular working heart experimental model to study metabolism in fetal pig hearts and in pig hearts obtained during the immediate newborn period. We have also adapted this experimental model to 1-d-old rabbit hearts (2, 3). Unfortunately, this experimental preparation cannot be used for the heart older than $1 \mathrm{~d}$, in which the foramen ovale is closed. The isolated heart model described in this study (Fig. 1) allows for the study of myocardial metabolism in a biventricular working heart beyond the immediate newborn period. Using this experimental model, we demonstrate that a substantial increase in overall exogenous energy substrate expenditure occurs if a right ventricular load is placed on 14-d-old rabbit hearts (a $50 \%$ increase). Furthermore, this ATP demand is met primarily by an increase in oxidation of fatty acids. Although lactate and glucose provide $41 \%$ of ATP production in hearts in which the right side of the heart is not perfused, if a right ventricular load is placed on the heart, ATP production from these sources does not increase substantially.

Our data demonstrate that the transition from preferential lactate oxidation to preferential fatty acid oxidation occurs within the first 2 wk after birth in the rabbit. As shown in Table 3, fatty acid oxidation provides over $50 \%$ of ATP requirements in 14-dold biventricular working hearts, whereas lactate oxidation provides only $15 \%$ of the ATP produced. This is in contrast to the 7 -d-old rabbit, in which lactate oxidation provides $49 \%$ of ATP production in isolated left ventricular working hearts perfused 

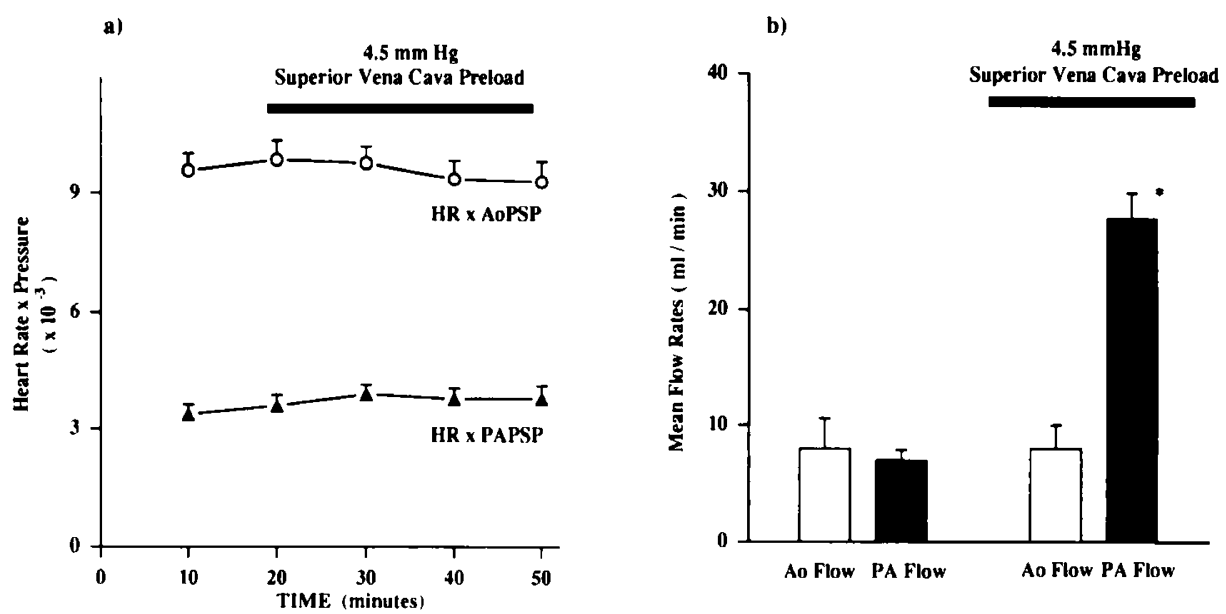

Fig. 3. Time course of both left and right ventricular function before and after initiation of $4.5 \mathrm{~mm} \mathrm{Hg}$ superior vena cava preload in isolated working hearts from 14-d-old rabbits. Hearts were perfused with $11 \mathrm{mM}$ glucose, $0.5 \mathrm{mM}$ lactate, $0.8 \mathrm{mM}$ palmitate, $3 \%$ albumin, and $100 \mu \mathrm{U} / \mathrm{mL}$ insulin as described in Materials and Methods. $a$, The upper curve represents heart rate $\times$ AoPSP $(H R \times A o P S P)$. The lower curve represents heart rate $\times$ PAPSP $(H R \times P A P S P)$. Values are the mean \pm SEM of 19 hearts. $b$, Aortic flow (Ao Flow) and pulmonary artery $(P A$ Flow $)$ measurements were made in a parallel series of hearts perfused under identical conditions except that measurements of oxidative metabolism were not made. The addition of Ao and PA flow without a superior vena cava preload represents the cardiac output (PA flow equals coronary flow). When a superior vena cava preload is applied, PA flow represents cardiac output and the difference between Ao and PA flow represents coronary flow. Values are the mean \pm SEM of three hearts.

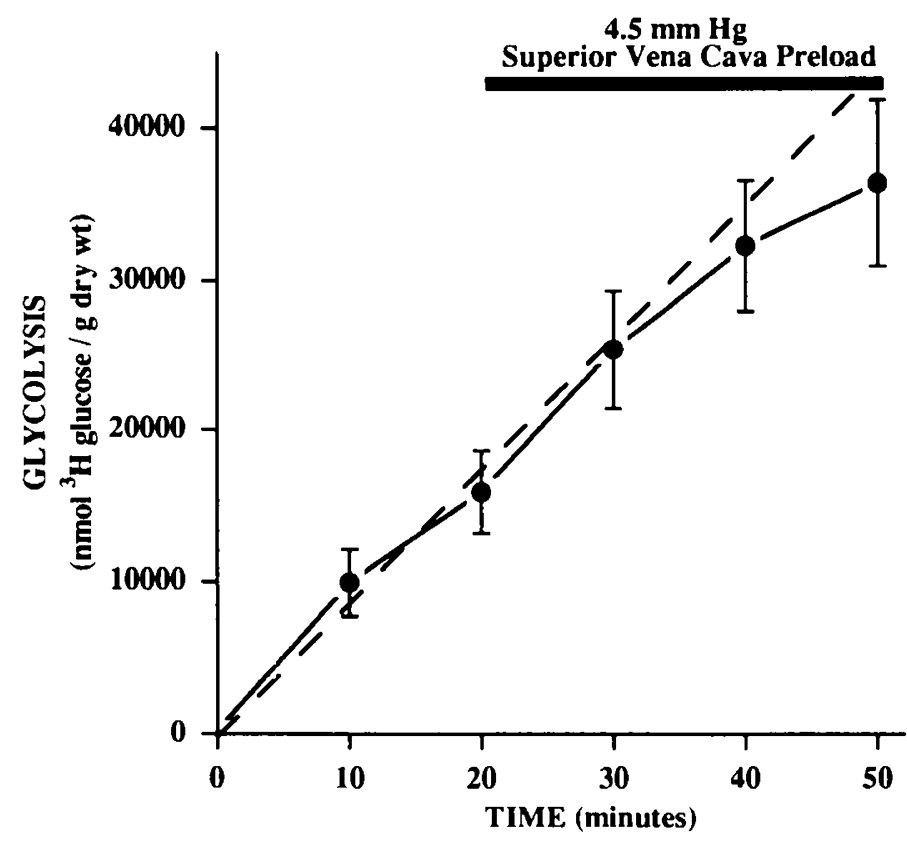

Fig. 4. Cumulative glycolysis before and after addition of a $4.5 \mathrm{~mm}$ $\mathrm{Hg}$ superior vena cava preload in isolated working hearts from $14-\mathrm{d}$-old rabbits. Hearts were perfused with $11 \mathrm{mM}\left[5-{ }^{3} \mathrm{H} / \mathrm{U}-{ }^{14} \mathrm{C}\right]-$ glucose, $0.5 \mathrm{mM}$ lactate, $0.8 \mathrm{mM}$ palmitate, $3 \%$ albumin, and $100 \mu \mathrm{U} / \mathrm{mL}$ insulin, as described in Materials and Methods. Values are the mean \pm SEM of 13 hearts. The dotted line represents the expected cumulative glycolysis rates without a superior vena cava preload.

with $11 \mathrm{mM}$ glucose, $2 \mathrm{mM}$ lactate, and $0.4 \mathrm{mM}$ palmitate. Between 1 and $7 \mathrm{~d}$ after birth, the ability of the heart to oxidize fatty acids dramatically increases $(2,3)$. In the presence of $2 \mathrm{mM}$ lactate, we have previously demonstrated that palmitate oxidation provides $39 \%$ of ATP production in 7-d-old heart (3). This compares to $36 \%$ of ATP production in the absence of a rightside load in this study (Table 2). Another observation from both 7-d-old and 14-d-old rabbits is that glucose oxidation rates are very low. This may be due to a slower maturation of glucose oxidation than of fatty acid oxidation in the newborn period. It should be noted that the transition of substrate use in the heart
Table 2. Steady state rates of glycolysis, glucose oxidation. lactate oxidation, and palmitate oxidation in isolated working hearts from 14-d-old rabbits*

\begin{tabular}{lcc}
\hline & \multicolumn{2}{c}{$\begin{array}{c}\text { Steady state rates } \\
\text { (nmol/g dry weight } \cdot \mathrm{min}^{-1} \text { ) }\end{array}$} \\
\cline { 2 - 3 } & - Right side & + Right side \\
\hline Glycolysis $(n=19)$ & $837.9 \pm 110.2$ & $790.0 \pm 107.8$ \\
Glucose oxidation $(n=8)$ & $86.5 \pm 10.7$ & $94.3 \pm 14.7$ \\
Lactate oxidation $(n=5)$ & $88.1 \pm 8.7$ & $126.2 \pm 12.7 \dagger$ \\
Palmitate oxidation $(n=7)$ & $28.2 \pm 2.5$ & $60.4 \pm 7.7 \dagger$ \\
\hline
\end{tabular}

* Hearts were perfused with $11 \mathrm{mM}$ glucose, $0.5 \mathrm{mM}$ lactate, $0.8 \mathrm{mM}$ palmitate, $3 \%$ albumin, and $100 \mu \mathrm{U} / \mathrm{mL}$ insulin. Glycolysis was measured from ${ }^{3} \mathrm{H}$-glucose, and glucose, lactate, and palmitate oxidation were measured from appropriately labeled ${ }^{14} \mathrm{C}$-substrates, as described in Materials and Methods. Values are the mean \pm SEM of the number of hearts shown in parentheses.

+ Significantly different from hearts in which the right side was not perfused.

from lactate to fatty acid oxidation after birth is in keeping with the changes in circulating levels of these substrates after birth. Fatty acid concentrations in the blood are low in fetal life but rapidly increase in the suckling period to levels that are normally seen in adults $(2,15)$. In contrast, circulating lactate levels are high in fetal life and decrease dramatically after birth $(15,16)$. The levels of lactate and palmitate used in this study are similar to the levels that are seen in the blood after birth $(2,16)$. Because of the increase in circulating fatty acids and the decrease in lactate levels, neonates must develop the metabolic pathways for efficient fatty acid oxidation in the heart. The exact subcellular changes responsible for the rapid maturation of fatty acid oxidation after birth, however, remain to be determined.

In addition to changes in lactate and fatty acid oxidation after birth, there are also marked changes in myocardial glucose use. If rabbit hearts obtained immediately after birth are perfused with glucose, lactate, and palmitate, glycolysis provides over $50 \%$ of myocardial ATP production (3). In contrast, the simultaneous measurement of glycolysis and glucose oxidation in neonatal heart demonstrated that glycolytic rates far exceeded rates of glucose oxidation $(3,14)$. This is suggestive of a decrease in flux through the PDC relative to flux through glycolysis. To date, 


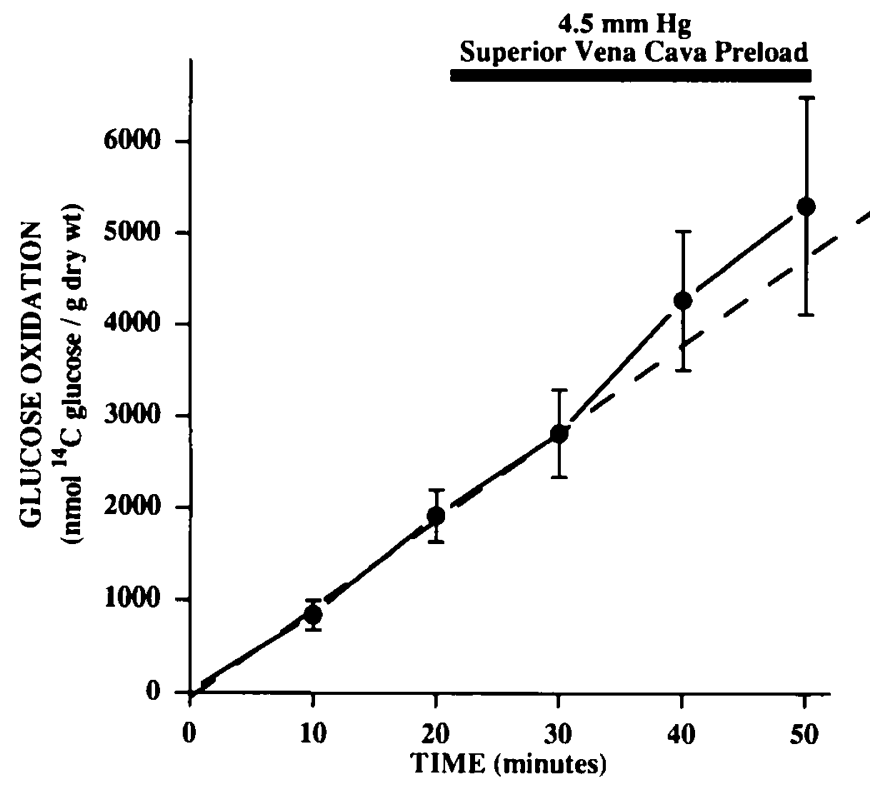

Fig. 5. Cumulative glucose oxidation before and after addition of a $4.5 \mathrm{~mm} \mathrm{Hg}$ superior vena cava preload in isolated working hearts from 14-d-old rabbits. Hearts were perfused with $11 \mathrm{mM}\left[5 \cdot{ }^{3} \mathrm{H} / \mathrm{U}-{ }^{14} \mathrm{C}\right] \mathrm{glucose}$, $0.5 \mathrm{mM}$ lactate, $0.8 \mathrm{mM}$ palmitate, $3 \%$ albumin, and $100 \mu \mathrm{U} / \mathrm{mL}$ insulin as described in Materials and Methods. Values are the mean \pm SEM of eight hearts. The dotted line represents the expected cumulative glucose oxidation without superior vena cava preload.

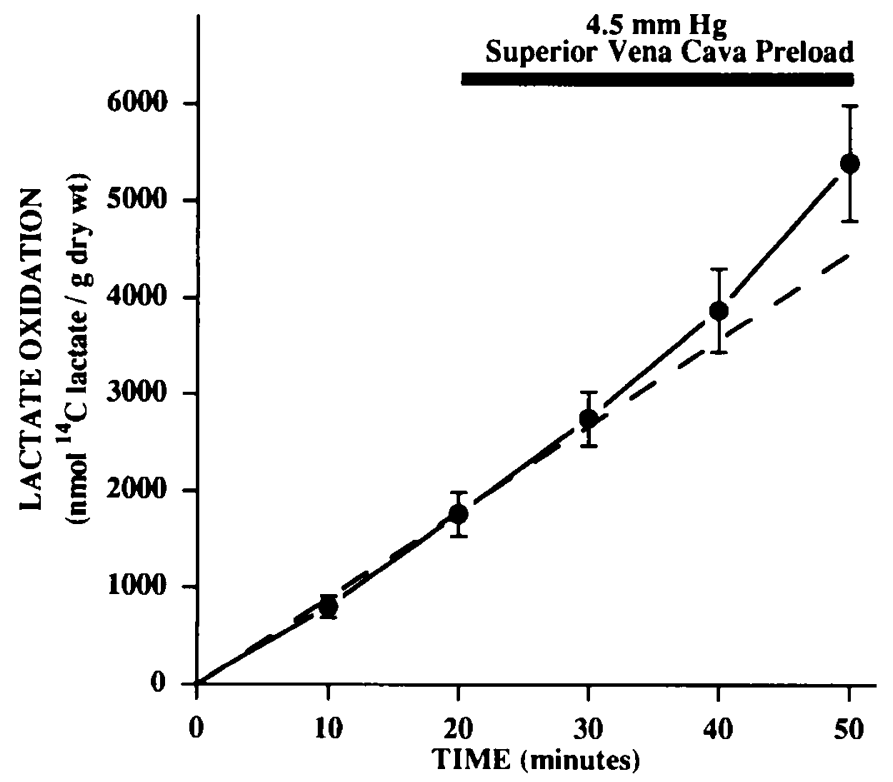

Fig. 6. Cumulative lactate oxidation before and after addition of a $4.5 \mathrm{~mm} \mathrm{Hg}$ superior vena cava preload in isolated working hearts from 14-d-old rabbits. Hearts were perfused with $11 \mathrm{mM}$ glucose, $0.5 \mathrm{mM}$ [1$\left.{ }^{14} \mathrm{C}\right]$-lactate, $0.8 \mathrm{mM}$ palmitate, $3 \%$ albumin, and $100 \mu \mathrm{U} / \mathrm{mL}$ insulin as described in Materials and Methods. Values are the mean \pm SEM of five hearts. The dotted line represents the expected cumulative lactate oxidation without superior vena cava preload.

however, no direct measurement of PDC activity has been reported in intact immature hearts. PDC activity, however, may be low during the suckling period, because the capacity for pyruvate oxidation, which reflects mainly PDC activity, increases in rat heart homogenates during maturation (17). We have also observed that pyruvate oxidation activity in heart homogenates from mice increases acutely after weaning (Itoi $\mathrm{T}$, unpublished observations).

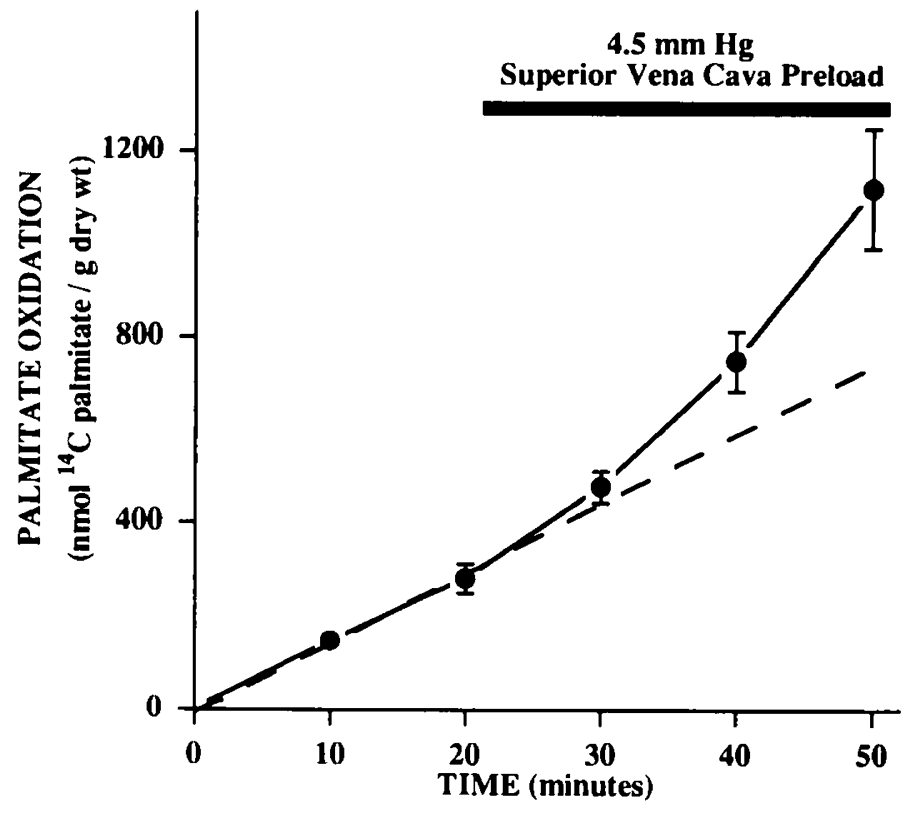

Fig. 7. Cumulative palmitate oxidation before and after addition of a $4.5 \mathrm{~mm} \mathrm{Hg}$ superior vena cava preload in isolated working hearts from 14-d-old rabbits. Hearts were perfused with $11 \mathrm{mM}$ glucose, $0.5 \mathrm{mM}$ lactate, $0.8 \mathrm{mM}\left[1 .{ }^{14} \mathrm{C}\right]$ palmitate, $3 \%$ albumin, and $100 \mu \mathrm{U} / \mathrm{mL}$ insulin as described in Materials and Methods. Values are the mean \pm SEM of seven hearts. The dotted line represents the expected cumulative palmitate oxidation without superior vena cava preload.

Although glucose oxidation rates are low in immature hearts, lactate oxidation rates can be substantial $(3,8)$. This may be related to the amount of specific isoforms of $\mathrm{LDH}$ in the heart. The M-form of the LDH isozyme, which is especially geared to serve as a pyruvate reductase in tissues that are dependent on glycolysis, predominates in neonatal heart muscle (18). In contrast, the properties of the $\mathrm{H}$-form isozyme make this enzyme more efficient for the oxidation of lactate in tissues with an aerobic metabolism. Although we do not know the distribution of LDH isozymes in 2-wk-old rabbit hearts, the fact that lactate can be oxidized in spite of low concentration of perfusate lactate suggests that $\mathrm{H}$-form $\mathrm{LDH}$ isozyme may predominant in rabbit hearts of this age.

Shortly after birth, the capacity of the heart to oxidize fatty acids increases in rats, rabbits, pigs, and calves $(1-4,19)$. Inasmuch as the rate of oxidation of octanoate, octanoylcarnitine, or palmitoyl carnitine is similar in mitochondria from hearts of fetal, newborn, and adult pigs $(12,20)$, the increase in fatty acid oxidation could be localized at the step of CPT 1 , which catalyzes the synthesis of acylcarnitine. CPT 1 activity itself, however, does not change with age in pig hearts (21), suggesting that regulation of CPT 1 may be important. Malonyl CoA, which is synthesized from acetyl CoA by acetyl CoA carboxylase, may be important in this regard, because it is a key regulator of CPT 1 in the heart $(22,23)$. In liver, a dramatic decrease in malonyl CoA concentration and sensitivity of CPT 1 to malonyl CoA occurs after birth (24). Whether this is the case in neonatal hearts has yet to be determined.

Because mechanical and energetic properties of the right ventricle are similar to those of the left ventricle (25), it is reasonable to assume that addition of volume load to the right ventricle should increase oxygen consumption of the heart. Ascuitto et al. (4) demonstrated a significant effect of ventricular end diastolic pressure on palmitate oxidation and suggested that the increased energy demands of the left ventricle were met partly through an increase in fatty acid oxidation. Although we did not see any change in right ventricular pressure in our hearts, it is likely that the area of the pressure-volume curve of the right ventricle increases when a right-side load is imposed on our hearts, result- 
Table 3. Steady state ATP production in 14-d-old rabbit hearts perfused with $11 \mathrm{mM}$ glucose, $0.5 \mathrm{mM}$ lactate, $0.8 \mathrm{mM}$ palmitate, $3 \%$ albumin, and $100 \mu \mathrm{U} / \mathrm{mL}$ insulin*

Steady state ATP production

$\left(\mathrm{nmol} / \mathrm{g}\right.$ dry weight $\left.\cdot \mathrm{min}^{-1}\right)$

\begin{tabular}{lcccc}
\cline { 5 - 5 } Source of ATP & - Right side & + Right side & - Right side & + Right side \\
\hline Glycolysis & $1676 \pm 220$ & $1582 \pm 214$ & 17 & 11 \\
Glucose oxidation & $3114 \pm 313$ & $3395 \pm 529$ & 31 & 23 \\
Lactate oxidation & $1585 \pm 157$ & $2271 \pm 229$ & 16 & 15 \\
Palmitate oxidation & $3643 \pm 322$ & $7797 \pm 993$ & 36 & 52 \\
Total ATP production & 10,018 & 15,045 & 100 & 100 \\
\hline
\end{tabular}

* Values were calculated from the steady state values shown in Table 2. Values of 2 ATP molecules produced per molecule of glucose passing through glycolysis, 36 ATP molecules produced per molecule of glucose oxidized, 18 ATP molecules produced per molecule of lactate oxidized, and 129 ATP molecules produced per molecule of palmitate oxidized were used in these calculations.

ing in an increase in oxygen consumption. When the cardiac work load is increased, the ATP demand increases and the intramitochondrial $\mathrm{NADH} / \mathrm{NAD}^{+}$ratio decreases. This relieves inhibition of both PDC and the enzymes of $\beta$-oxidation. Increased ATP demand during an increase in cardiac work load accelerates either glucose or fatty acid oxidation if these substrates are used individually in the isolated perfused adult rat heart (11). When both glucose and fatty acids are provided to the heart, fatty acids decrease glucose uptake, phosphofructokinase activity, and PDC activity. In isolated working adult rats hearts, we have recently demonstrated that increasing work, either by increasing afterload or by inotropic stimulation, results in the extra ATP production being primarily derived from glucose oxidation (Collins-Nakai RL, Lopaschuk GD, unpublished observations). This suggests that even though fatty acids inhibit PDC an increase in intramitochondrial acetyl-CoA demand can be met from glucose oxidation. Significant increases in PDC activity are also observed in the electrically stimulated heart from adult guinea pig perfused with glucose plus fatty acid (26). If lactate oxidation is considered, it has been shown that lactate inhibits fatty acid oxidation, although fatty acids do not dramatically depress lactate oxidation (9). This is because LDH activity is considered to be marginally affected by the increase in NADH seen during an increase in fatty acid oxidation (27). From this line of evidence, it appears that in the adult heart provided with glucose, fatty acid, and lactate, the increases in ATP production during increased work loads are observed through activation of PDC. In contrast, the result from this study would suggest that the most sensitive pathway for increasing ATP production in 14-d-old rabbit hearts is through the $\beta$-oxidation pathway. The major effect of increasing right ventricle work was an increase in fatty acid oxidation, which resulted in a $50 \%$ increase in ATP production in hearts. Acceleration of PDC flux by exogenous carbohydrates (both glucose oxidation and lactate oxidation) was not substantial when a right-side load was added to the heart. Whether this was due to the fact that the PDC is not yet fully mature has yet to be determined.

In summary, this study demonstrated that by $2 \mathrm{wk}$ of age, glucose and fatty acid oxidation are the major source of energy in rabbit hearts. Addition of a right-side perfusion, however, results in a selective increase in ATP production from palmitate oxidation. These observations suggest that by $2 \mathrm{wk}$ of age in the rabbit, fatty acids become the primary energy substrate and the capacity of the heart to oxidize glucose has not fully matured.

\section{REFERENCES}

1. Werner JC, Sicard RE, Schuler HG 1989 Palmitate oxidation by isolated working fetal and newborn pig hearts. Am J Physiol 256:E315-E321

2. Lopaschuk GD, Spafford MA 1990 Energy substrate utilization by isolated working hearts from newborn rabbits. Am J Physiol 258:H1274-H1280
3. Lopaschuk GD, Spafford MA, Marsh D 1991 Glycolysis is predominant source of myocardial ATP production immediately after birth. Am J Physiol $261 \cdot \mathrm{H} 1698-\mathrm{H} 1705$

4. Ascuitto RJ, Ross-Ascuitto NT, Chen V, Downing SE 1989 Ventricular function and fatty acid metabolism in neonatal piglet heart. Am J Physio 256:H9-H15

5. Wittels B, Bressler R 1965 Lipid metabolism in newborn hearts. J Clin Invest 44:1639-1646

6. McMillan-Wood J 1975 Carnitine palmitoyltransferase in neonatal and adult heart mitochondria. J Biol Chem 250:3062-3066

7. Fisher DJ, Heymann MA, Rudolph AM 1981 Myocardial consumption of oxygen and carbohydrates in newborn sheep. Pediatr Res 15:843-846

8. Werner JC, Sicard RE 1987 Lactate metabolism of isolated, perfused fetal, and newborn pig hearts. Pediatr Res 22:552-556

9. Liu MS, Spitzer JJ 1978 Oxidation of palmitate and lactate by beating myocytes isolated from adult dog heart. J Mol Cell Cardiol 10:415-426

10. Issrkutz Jr B, Miller HI, Paul P, Rodahal K 1965 Effect of lactic acid on free fatty acids and glucose oxidation in dogs. Am J Physiol 209:1137-1144

11. Neely JR, Morgan HE 1974 Relationship between carbohydrate and lipid metabolism and the energy balance of heart muscle. Annu Rev Physiol $36: 413-459$

12. Werner JC, Whitman V, Vary TC, Fripp RR, Musselman J, Schuler HG 1983 Fatty acid and glucose utilization in isolated working newborn pig heart. Am J Physiol 1244:E19-E23

13. Saddik M, Lopaschuk GD 1991 Myocardial triglyceride turnover and contribution to energy substrate utilization in isolated working rat hearts. J Biol Chem 266:8162-8170

14. Itoi T, Lopaschuk GD 1993 Glucose use in newborn rabbit hearts reperfused following global ischemia. Am J Physiol 265:H427-H433

15. Girard J, Ferre P, Pegorier JP, Duee PE 1992 Adaptations of glucose and fatty acid metabolism during perinatal period and suckling-weaning transition. Physiol Rev 72:507-562

16. Medina JM 1985 The role of lactate as an energy substrate for brain during the early neonatal period. Biol Neonate 48:237-244

17. Veerkamp JH, Glatz JFC, Wagenmakers AJM 1985 Metabolic changes during cardiac maturation. Basic Res Cardiol 80 (suppl 2):111-114

18. Brooks WW, Ekblom B, Bing OHL 1985 Comparative response of 2-week and 6-week old rabbit myocardium to hypoxia. J Dev Physiol 7:229-240

19. Lockwood EA, Bailey E 1970 Fatty acid utilization during development of the rat. Biochem J 120:49-54

20. Warshaw JB 1972 Cellular energy metabolism during fetal development. IV. Fatty acid activation, acyl transfer and fatty acid oxidation during development of the chick and rat. Dev Biol 28:537-544

21. Wolfe RG, Maxwell CV, Nelson EC 1978 Effect of age and dietary fat levels on fatty acid oxidation in the neonatal pig. J Nutr 108:1621-1634

22. McGarry JD, Leatherman GF, Foster DW 1978 Carnitine palmitoyltransferase 1. The site of inhibition of hepatic fatty acid oxidation by malonyl $\mathrm{CoA}$. J Biol Chem 253:4128-4136

23. Saggerson ED 1982 Carnitine acyltransferase activities in rat liver and heart measured with palmitoyl CoA and octanoyl CoA. Biochem J 202:397-405

24. Prip-Buss C, Pegorier J-P, Duee P-H, Kohl C, Girard J 1990 Evidence that the sensitivity of carnitine palmitoyltransferase 1 to inhibition by malonyl $\mathrm{CoA}$ is an important site of regulation of hepatic fatty aeid oxidation in the fetal and newborn rabbit. Biochem J 269:409-415

25. Yamada O, Kamiya T, Suga H 1989 Right ventricular mechanical and energetic properties. Jpn Circ J 53:1260-1268

26. Hansford RG, Hogue B, Prokapczuk A, Wasilewska E, Ledartowiski B 1990 Activation of pyruvate dehydrogenase by electrical stimulation, and low-Na perfusion of guinea pig hearts. Biochim Biophys Acta 1018:282-286

27. Everest J, Kaplan NO 1975 Mechanism of action and biological functions of various dehydrogenase isozymes. In: Markert CL (ed) Isozymes II Physiolog. ical Function. Academic Press, New York, pp 29-43 